\title{
Large Deformation Finite Element Analyses in Geotechnical Engineering
}

Manuscript submitted to Computers and Geotechnics on 15/09/2014

Revised manuscript submitted on 14/11/2014

Accepted 12/12/2014

Dong Wang (corresponding author) *

Research Assistant Professor

Email: dong.wang@uwa.edu.au

Tel: +61 864883447

\section{Britta Bienen *}

Associate Professor, ARC Postdoctoral Fellow

Email: britta.bienen@uwa.edu.au

\section{Majid Nazem ${ }^{\wedge}$}

Senior Lecturer

Email: majidreza.nazem@newcastle.edu.au

\section{Yinghui Tian *}

Research Assistant Professor

Email: yinghui.tian@uwa.edu.au

Jingbin Zheng *

PhD candidate

Email: 21102353@student.uwa.edu.au

\section{Tim Pucker ${ }^{+}$}

Engineer

Email: t.pucker@ims-ing.de

\author{
Mark F. Randolph * \\ Winthrop Professor \\ Email: mark.randolph@uwa.edu.au
}


${ }^{*}$ Centre for Offshore Foundation Systems and ARC CoE for Geotechnical Science and Engineering The University of Western Australia

35 Stirling Hwy

Crawley, WA 6009, Australia

Fax: +61 864881044

${ }^{\wedge}$ ARC CoE for Geotechnical Science and Engineering

The University of Newcastle

Callaghan, NSW 2308, Australia

+ IMS Ingenieurgesellschaft mbH

A company in the Ramboll Group

Stadtdeich 7

20097 Hamburg

Germany 


\section{ABSTRACT}

Geotechnical applications often involve large displacements of structural elements, such as penetrometers or footings, in soil. Three numerical analysis approaches capable of accounting for large deformations are investigated here: the implicit remeshing and interpolation technique by small strain (RITSS), an efficient Arbitrary Lagrangian-Eulerian (EALE) implicit method and the Coupled Eulerian-Lagrangian (CEL) approach available as part of commercial software. The theoretical basis and implementation of the methods are discussed before their relative performance is evaluated through four benchmark cases covering static, dynamic and coupled problems in geotechnical engineering. Available established analytical and numerical results are also provided for comparison purpose. The advantages and limitation of the different approaches are highlighted. The RITSS and EALE predict comparable results in all cases, demonstrating the robustness of both in-house codes. Employing implicit integration scheme, RITSS and EALE have stable convergence although their computational efficiency may be low for high-speed problems. The CEL is commercially available, but user expertise on element size, critical step time and critical velocity for quasi-static analysis is required. Additionally, mesh-independency is not satisfactorily achieved in the CEL analysis for the dynamic case.

KEYWORDS: finite element method; large deformation; arbitrary Lagrangian-Eulerian; Eulerian method; penetrometers; consolidation; dynamic 


\section{INTRODUCTION}

Large deformation analysis is one of the most challenging topics in computational geomechanics, particularly in problems involving complicated structure-soil interaction. A qualified large deformation approach must quantify the geometric evolvement induced by changes in the surface profile and distortion of separate soil layers. The Total Lagrangian (TL) and the Update Lagrangian (UL) finite element (FE) approaches may be the most popular numerical methods in geotechnical engineering. However, the calculation must stop even if only few elements within the mesh become seriously distorted.

To capture large deformation phenomena that occur frequently in geotechnical practice, the traditional numerical approaches established within Lagrangian framework are replaced by, for example, those based on the framework of Arbitrary Lagrangian-Eulerian (ALE). Depending on the discretisation of materials, the ALE FE approaches focusing on geotechnical applications are divided into two categories: mesh-based methods such as in van den Berg et al. (1996), Hu and Randolph (1998a), Susila and Hryciw (2003) and Sheng et al. (2009), which are the concern of this paper; and particle-based methods such as material point method (Sulsky et al., 1995; Beuth et al., 2011). In the mesh-based ALE approach with the operator-split technique, each incremental step includes a Lagrangian phase and an Eulerian phase. The Lagrangian calculation is conducted on the deformable mesh, and then the deformed mesh is updated by adjusting the positions of nodes but maintaining the topology, or is replaced via mesh regeneration. Subsequently, the field variables (e.g. stresses and material properties) are mapped from the old mesh to the new mesh, representing Eulerian flow through the mesh. Compared with static analysis, two more field variables, nodal velocities and accelerations, need to be mapped in a dynamic analysis. For coupled analysis of fully saturated soils, effective stresses and excess pore pressure, rather than total stresses, are mapped.

Among a variety of ALE approaches, three FE methods widely used in research and industry for analysis of geotechnical engineering problems are discussed in this paper: the remeshing and interpolation technique by small strain (RITSS) developed at the University of Western Australia, an efficient ALE (termed EALE) approach developed at the University of Newcastle and the Coupled Eulerian-Lagrangian (CEL) approach available in the commercial software Abaqus/Explicit. It is recognised that other large deformation FE approaches exist. However, the paper is not intended to detail the theoretical formulation of different large deformation methods. Instead, its concern is to provide an insight into the large deformation algorithms by discussing the advantages and disadvantages of the three approaches. 
(1) The RITSS approach was originally presented by Hu and Randolph (1998a), in which the deformed soil is remeshed periodically and Lagrangian calculation is implemented through an implicit time integration scheme. The advantage of RITSS is that the remeshing and interpolation strategy can be coupled with any standard FE program, such as the locally developed program AFENA (Carter and Balaam, 1995) and the commercial package Abaqus/Standard, through userwritten interface codes. The potential of the approach has been highlighted by varied two-dimensional (2D) and three-dimensional (3D) applications of monotonic and cyclic penetration of penetrometers (Lu et al., 2004; Zhou and Randolph, 2009), penetration of spudcan foundations for mobile jack-up rigs (Hossain et al., 2005; Hossain and Randolph, 2010; Yu et al., 2012), lateral buckling of pipelines (Wang et al., 2010b; Chatterjee et al., 2012) and uplift capacity and keying of mooring anchors (Song et al., 2008; Wang et al., 2010a; 2011; 2013a; Wang and O’Loughlin, 2014; Tian et al., 2014b; c). More recently, RITSS was extended from static to dynamic analyses (Wang et al., 2013c).

(2) The EALE approach is based on the operator split technique proposed by Benson (1989), and tailored to geomechanics problems by Nazem et al. (2006) in the in-house software SNAC. This method is a well-known variant of r-adaptive FE methods, which have been designed to eliminate possible mesh distortion by changing and optimising the location of nodal points without modifying the topology of the mesh. The EALE approach has been extended to the solution of consolidation problems (Nazem et al., 2008), as well as to the dynamic analysis of a wide range of geotechnical problems (Nazem et al., 2009a; Nazem et al., 2012; Sabetamal et al., 2014).

(3) In the CEL method the element nodes move temporarily with the material during a Lagrangian calculation phase, which is followed by mapping to a spatially 'fixed' Eulerian mesh (Daussault Systèmes, 2012). The calculation in the Lagrangian phase is conducted with an explicit integration scheme. In contrast to RITSS and EALE, an element in CEL may be occupied by multiple materials fully or partially, with the material interface and boundaries approximated by volume fractions of each material in the element. The CEL method has been used by a number of researchers to investigate the penetration of spudcan foundations in various soil stratigraphies (Qiu and Grabe, 2012; Tho et al., 2012, 2013; Pucker et al., 2013; Hu et al., 2014) and uplift capacity of rectangular plates (Chen et al., 2013). The comparatively rigid structural part (i.e. spudcan, anchor or similar) is usually modelled as a Lagrangian body and the soils as Eulerian materials. A 'general contact' algorithm by means of an enhanced immersed boundary method describes frictional contact between Lagrangian and Eulerian materials. Advanced soil constitutive models, such as a hypoplastic model for sand, a viscohypoplastic model for clay and a modified Tresca model considering strain softening and ratedependency of clay, have been incorporated into the CEL (Qiu and Grabe, 2012; Pucker and Grabe, 
2012; Hu et al., 2014). To date, CEL is limited to total stress analysis, although it can be modified to obtain pore pressures under undrained conditions (Yi et al., 2012).

The purpose of this paper is to assess the performance and limitations of the RITSS, EALE and CEL approaches through four deliberately-chosen benchmark cases covering static, consolidation and dynamic geotechnical applications. The analytical and numerical results, where possible, are also supplemented for comparison purposes.

\section{THEORETICAL BACKGROUNDS OF RITSS, EALE AND CEL}

All three approaches are classified as operator split in computational mechanics, i.e. a Lagrangian phase is followed by an Eulerian/convection phase (Benson, 1989). However, the implementation of each individual approach is facilitated by specific time integration schemes for the governing equations, remeshing strategy and mapping technique (see Table 1), which results in certain advantages and disadvantages of each approach for particular problems.

The mathematic frameworks of the three approaches are provided in separate Appendices, in order to remain conciseness of narration.

\subsection{RITSS}

In the RITSS approach, the convection of field variables is achieved by polynomial interpolation. Irrespective of whether the field variables are mapped to the new integration points (e.g. total or effective stresses and material properties) or to the new nodes (e.g. velocities, accelerations and pore pressure), the interpolation is always conducted locally within an old element, an old element patch or a triangle connecting old integration points, depending on the mapping technique adopted. The computational effort of mapping is thus negligible compared with that of the Lagrangian calculation in an implicit integration scheme, especially for large-scale 3D problems. The elements are expected to be at least quadratic in order to retain mapping accuracy. The force equilibrium and consolidation equations are not satisfied inherently at the commencement of each incremental step, due to the 'averaging' essence of polynomial interpolation. However, any unbalance in the governing equations is usually diminished effectively through the next step and no significant accumulation of errors has been observed. The implicit scheme and requirement for high-order elements highlights that the RITSS is an appropriate option for static or low-speed problems, which has been proved convincingly in extensive applications of the RITSS method. For high-speed problems such as dynamic compaction of foundation, the effectiveness and efficiency of RITSS becomes questionable since a number of soil elements may undergo sudden and severe distortion. The popular ALE approaches based on linear elements and explicit schemes are expected to be a better option for these applications. 
The geometries of soil and associated structures may be so complex that the frequent mesh regeneration becomes onerous or the deformed geometries cannot be meshed automatically on the basis of a user program coded a priori. To date, however, this has not impeded any problems modelled using the RITSS method. The soil in previous 2D applications was discretised with triangular or quadrilateral elements (Hu and Randolph, 1998a; Zhou and Randolph, 2009; Wang et al., 2013b), whilst tetrahedral elements rather than octahedral elements were used in 3D models due to limitations of state-of-the-art meshing techniques (Wang et al., 2011, 2014). Despite an h-adaptive technique adopted in Hu et al. (1999) to optimize the mesh, the meshes in Abaqus-based RITSS analyses were generated based on users' experience and observation of trial calculations on a coarse mesh. Abaqus was called to generate the mesh and conduct the UL calculation in the following RITSS analyses.

The accuracy of large deformation analysis using RITSS or EALE depends largely on the mapping technique employed to map field variables from the old to new mesh. Three interpolation techniques were explored in previous simulations: the modified unique element method (MUEM, Hu and Randolph, 1998b), the superconvergent patch recovery (SPR, Zienkiewicz and Zhu, 1993) and recovery by equilibration of patches (REP, Boroomand and Zienkiewicz, 1997). In MUEM, the field variables such as stresses and material properties are mapped directly from the old integration points to the new integration points. In contrast, the SPR and REP techniques are aimed at recovering stresses from the old integration points to the old element nodes. After that, the old element containing each new integration point is searched for and then the stresses are then interpolated from the old element nodes. In general, these three techniques provide comparable accuracies. The costs of the mapping techniques are minimal compared with that of the Lagrangian calculation, since the interpolation is conducted locally within the old mesh. For a 3D interpolation with element number of $~ 30,000$, mapping takes less than 20 s when run on a PC with a CPU frequency of $3.4 \mathrm{GHz}$. In contrast, in the ALE approaches that use an explicit scheme, the optimum equation to minimise the mapping error of each field variable is solved globally, which leads to a significantly higher computational effort for the Eulerian phase (Benson, 1989).

Most recently, Tian et al. (2014a) presented a simple implementation of RITSS which avoids any need for user-defined code by utilising an Abaqus in-built function termed 'mesh-to-mesh solution mapping' for interpolation. The function first extrapolates the stresses from the old integration points to old element nodes, and the stresses at each old element node are then obtained by averaging extrapolated values from all old elements abutting the node. Stresses at new integration points are then interpolated from the nodes of the old elements. The numerical accuracy of the simple RITSS was verified through static benchmark problems with Tresca material; however, its application in static problems with more complex soil models and dynamic problems is yet to be investigated. 


\subsection{EALE}

The EALE method is based on the idea of separating the material and mesh displacements to avoid mesh distortion in a Lagrangian method. In the so-called coupled ALE method this separation usually introduces unknown mesh displacements into the governing global system of equations, doubling the number of unknown variables and leading to significantly more expensive analyses. On the other hand, the decoupled ALE method, or the operator-split technique, first solves the material displacements via the equilibrium equation and then computes the mesh displacements through a mesh refinement technique. In the UL phase the incremental displacements are calculated for a given load increment by satisfying the principle of virtual work. It is notable that in a large deformation analysis, the stress-strain relations must be frame independent to guarantee that possible rigid body motions do not induce extra strains within the material. This requirement, known as the principle of objectivity, is satisfied by introducing an objective stress-rate into the constitutive equations. An important feature of an objective stress-rate is that it should not change the values of stress invariants, thus guaranteeing that a previously yielded point remains on the yield surface after being updated due to rigid body motion. Nazem et al. (2009b) proposed alternative algorithms for integrating rate-type constitutive equations in a large deformation analysis and concluded that it is slightly more efficient to apply rigid body corrections while integrating the constitutive equations. This strategy is adopted in this study. After satisfying equilibrium, the UL phase is usually finalised by updating the spatial coordinates of the nodal points according to incremental displacements. Unfortunately, the continuous updating of nodal coordinates alone may cause mesh distortion in regions with relatively high deformation gradients. Hence, the distorted mesh is refined using a suitable mesh refinement technique.

Most mesh refinement techniques are based on special mesh-generation algorithms, which must consider various factors such as the dimensions of the problem, the type of elements to be generated and the regularity of the domain. Developing such algorithms for any arbitrary domain is usually difficult and costly. Moreover, these algorithms do not preserve the number of nodes and number of the elements in a mesh and they may cause significant changes in the topology. A general method for determining the mesh displacements based on the use of an elastic analysis was presented by Nazem et al. (2006). In this method, the nodes on all boundaries of the problem, including the boundaries of each body, the material interfaces and the loading boundaries, are first relocated along the boundaries, resulting in prescribed values of the mesh displacements for those nodes. With the known total displacements of these boundary nodes, an elastic analysis is then performed using the prescribed displacements to obtain the optimal mesh and hence the mesh displacements for all the internal nodes. An important advantage of this mesh optimisation method is its independence of element topology 
and problem dimensions. This method uses the initial mesh during the analysis and does not regenerate a mesh, i.e. the topology of problem does not change, and hence can be implemented easily in existing FE codes (Nazem et al., 2006; Nazem et al., 2008). After mesh refinement, all variables at nodes and integration points are transferred from the old (distorted) mesh into the new (refined) mesh.

\subsection{CEL}

Both Eulerian and Lagrangian bodies can be included in a CEL model, but no convection operation is performed on the Lagrangian materials (Daussault Systèmes, 2012); i.e. in contrast to other ALE approaches, the original mesh is retained. No re-meshing is required and severe mesh distortion causing numerical instability cannot occur in a CEL analysis (Tho et al., 2012). Materials not expected to undergo significant deformation are discretised using Lagrangian elements, while materials that may experience large displacements (i.e. soils in geotechnical problems) are represented as Eulerian materials that 'flow' through the elements of the stationary mesh. Elements may be fully or partially occupied, or completely void. As a consequence, material boundaries (i.e. soil layers and structure-soil interface) do not necessarily correspond with Eulerian element boundaries. In order to capture soil surface heave in a geotechnical problem, a layer of void elements should therefore be included. Application of pressure loading or non-zero displacements on the soil surface is not possible directly, but this can be circumvented if desired.

CEL analyses are dynamic with an explicit integration scheme, which implies that the time duration modelled is meaningful and directly affects the simulation time. Explicit calculations do not require iterative procedures but are not unconditionally stable. Numerical stability is guaranteed by introduction of the critical time step size, which is roughly proportional to the smallest element length and inversely proportional to the square root of the elastic stiffness of the material. When the explicit algorithm is utilised for quasi-static analysis, accelerations in the model must be sufficiently slow to avoid undesired inertial effects. While Daussault Systèmes (2012) stipulates an analysis to be quasistatic if the energy balance remains below $10 \%$, this has not been found to be a satisfactory criterion in obtaining an accurate quasi-static response in geotechnical problems. Rather, a convergence study for the combined effects of velocity and mesh density is required through a well-designed verification for each particular problem to achieve a suitable compromise between accuracy in the quasi-static response and computational efficiency. Note that this applies even if the constitutive relation is rateindependent. Discussion of mesh density, velocity and critical time step in particular problems can also be found in Qiu and Henke (2011) and Tho et al. (2012).

Since an Eulerian element may contain more than one material, the convection in CEL is more complex than that in the other two approaches. The convection must be monotonic, i.e. the ranges of 
the field variables are not enlarged during the convection (Benson, 1992). A second-order convection technique satisfying the monotonicity is suggested (Daussault Systèmes, 2012).

The current CEL implementation in Abaqus is only available for 3D models, i.e. plane strain or axisymmetric problems must be simulated in 3D (even if only a depth of one element is required to be modelled for plane strain problems and symmetry can still be taken advantage of in the case of axial symmetry as shown in Andresen and Khoa (2012)). Therefore for 2D problems, the computational efficiency of CEL cannot be compared with the RITSS and EALE approaches. CEL is, however, much more accessible than both RITSS and EALE as it is part of commercially available software. No programming is required by the user, and the FE model can be built entirely through a graphical interface (though the option of coding a script instead also exists).

\section{COMPARISONS}

The robustness and reliability of the three large deformation approaches have been assessed through four benchmark cases, in which large deformations of the soil were induced by simple or complex trajectories of the structural element. All the cases, which have clear geotechnical background, are summarized in Table 2. To retain consistency between the three approaches, the definitions of stresses and strains followed finite strain theory and a UL formulation was adopted. Correspondingly, the strains and stresses on the deformed configuration were measured with the rate of deformation and Cauchy stress, which are work conjugate. The Jaumann rate was selected as the objective stress rate. In all four benchmark cases, the structural elements were idealised as rigid bodies due to their much higher stiffness relative to the soil. Clayey soils rather than sands were explored, allowing focus on comparison of the performance of the three numerical approaches without the additional complication of a constitutive relationship that appropriately captures the behaviour of sandy soils.

(i) The static and dynamic analyses, cases 1, 2 and 4 in Table 2, were performed under undrained conditions using a total stress approach, with the soils modelled as elastic-perfectly plastic materials with either a von Mises or Tresca yield criterion. Poisson's ratio was taken as 0.49 to approximate constant soil volume under undrained conditions and the coefficient of earth pressure at rest was taken as $K_{0}=1$. The soil domains and structural elements were discretised with quadratic triangular elements with three or six integration points respectively for the RITSS and EALE approach, whilst linear hexahedral elements with reduced integration were used in the CEL models.

(ii) In the consolidation problems, Case 3, the effective stress-strain relationship of soil was idealized as linear elastic. The soil was discretised with quadrilateral elements with four integration points in the RITSS analyses and triangles with six integration points in EALE. The displacements and excess pore pressure in the element were interpolated with second- and first-order accuracy, respectively. 
The rough surface footing in Case 3 did not appear physically in the simulations, but was represented by appropriate boundary conditions. The CEL approach is not available for consolidation problems, so the comparison was conducted between RITSS and EALE only.

\subsection{Cone penetration}

The cone penetrometer is arguably the most widely used in-situ tool to obtain the soil stratigraphy and corresponding physical and mechanical properties. For cone penetration tests in soft clays, the undrained shear strength of soil, $s_{u}$, can be deduced from the net penetration resistance by means of a theoretical or calibrated bearing factor $N_{\mathrm{kt}}$. The bearing factor has been investigated using various ALE approaches with implicit or explicit schemes (Walker and Yu, 2006; 2010; Liyanapathirana, 2009; Lu et al., 2004; Pucker et al., 2013). Here, a benchmark case in Walker and Yu (2006; 2010) was replicated: a standard cone with projected area of $A=1000 \mathrm{~mm}^{2}$ (shaft diameter $D=35.7 \mathrm{~mm}$ ) and apex angle of $60^{\circ}$ was penetrated into weightless clay (though a density has to be specified for the CEL analysis as this influences the initial estimate of stiffness and hence the critical time step) under undrained conditions; the cone was assumed to be smooth; the soil strength was uniform with $S_{\mathrm{u}}=10 \mathrm{kPa}$; and the soil rigidity index $G / s_{\mathrm{u}}=100$, where $G$ is the elastic shear modulus. The soil was modelled with the von Mises yield criterion. Figure 1 illustrates the meshes used in the RITSS, EALE and CEL analyses. Typical element sizes of $0.05 \mathrm{D}$ around the penetrometer were found to produce accurate results in all three numerical approaches. Nazem et al. (2012) previously showed that the mesh in Figure 1b, including 5000 quadratic elements, can predict reasonable results in the EALE analysis. While no difference is discernible in the contact around the embedded part of the cone, the soil is forced to remain attached to the penetrometer in the RITSS analyses whereas separation is allowed in the CEL simulation, resulting in differences in the zone of heave. This, however, is a detail that has little effect on the total penetration resistance. Note that in contrast to the Lagrangian-based methods, in CEL the soil surface is not defined exactly but evaluated based on the volume fraction of each material in each element, and its representation can be adjusted by the user.

The normalised resistance-displacement curves obtained by the different approaches are shown in Figure 2. The penetration velocity of the cone was taken as $v=0.1 \mathrm{~m} / \mathrm{s}$ in the CEL analysis. The resistance obtained from RITSS is slightly higher than that of Walker and Yu (2006), but moderately lower than Walker and Yu (2010). Both analyses by Walker and Yu (2006, 2010) are based on the ALE function in Abaqus/Explicit, however, the penetration resistance was calculated using the averaged stress from the integration points below the cone face in the former and using the nodal forces at the cone face in the latter (Yu, 2014, pers. comm.). The EALE analysis predicts slightly higher resistance than the RITSS, whilst the resistances from the CEL agree with those in Walker and Yu (2010). The resistance-displacement curve from the RITSS analysis is remarkably smooth, while 
results of the explicit algorithms show some computational noise (the appearance of which depends on the sampling rate as well as parameters defining the analysis). All three methods predict that the ultimate bearing capacity is approached at $\sim 9 D$. The bearing capacity factor, $N_{\mathrm{kt}}$, is estimated as 11.1 , 10.2 and 9.8 by CEL, EALE and RITSS, respectively. The analytical solution from the strain path method is 9.7 (Teh and Houlsby, 1991). Liyanapathirana (2009) conducted a series of large deformation analyses using ALE in Abaqus/Explicit with a capacity factor of 9.4 suggested via a fitting equation.

For the CEL analysis, convergence of the solution was investigated not only in terms of mesh refinement, but also as a function of the penetration velocity. A penetration velocity of $0.1 \mathrm{~m} / \mathrm{s}$ was found to be sufficiently slow to obtain convergence of the quasi-static response, while a ten-fold increase in penetration velocity resulted in higher resistance (Figure 3). Further reduction of the penetration velocity, on the other hand, produced only minor reduction in the calculated response, so not justifying the additional computational expense (the case of $v=0.01 \mathrm{~m} / \mathrm{s}$ was not completed due to the approximately tenfold increase in runtime compared to the same analysis performed at $v=0.1$ $\mathrm{m} / \mathrm{s}$ ).

Similar to mesh convergence, which needs to be established for the problem under consideration, the effect of the penetration velocity requires problem-specific investigation. Besides the element length and velocity, the material stiffness influences the critical time step that is automatically calculated, based on the criterion that the wave travel is limited to one element per increment. In analyses with nonlinear material stiffness, the automatically determined critical time step may be reduced to limit numerical oscillations. However, reducing the time step of this particular analysis had negligible influence, since Abaqus/Explicit applies some damping through bulk viscosity to filter out high frequency oscillations. The stability of the CEL analysis may benefit from a moderate increase in the linear bulk viscosity term from the default value. Though CEL is commercially available and thus it is relatively easy to run an analysis, as with any numerical analysis approach its intricacies need to be understood and experience needs to be attained to apply this technique confidently to geotechnical problems.

\subsection{Buckling of a pipeline}

Pipelines in deep water are generally laid untrenched on the seabed but embed shallowly due to selfweight and additional loads. The pipelines are also designed to accommodate thermal expansion which is achieved through controlled lateral buckling. In contrast to the simple trajectory of cone penetration in soil, the pipe during large-amplitude lateral buckling may move upwards toward the soil surface or dive deeply into the soil, depending on combined effects related to the embedment depth, vertical force applied and soil strength. In this case, a pipe with diameter of $D=0.6 \mathrm{~m}$ was 
initially placed on the seabed surface. The soil was normally consolidated clay with undrained strength increasing linearly with depth $\mathrm{z}$ (in $\mathrm{m}$ ) according to $s_{\mathrm{u}}=1+1.2 \mathrm{z} \mathrm{kPa}$.

The Tresca model was employed with a rigidity index $G / S_{u}=167$. The submerged unit weight of soil was $\gamma^{\prime}=6.5 \mathrm{kN} / \mathrm{m}^{3}$. The pipe-soil interaction was described as frictional contact based on Coulomb’s law, relative to the local normal stress. The Coulomb friction coefficient was taken as 0.1 , without a maximum shear stress specified on the interface. The pipe underwent a vertical movement of $0.4 D$ to represent partial embedment during the laying process. The corresponding vertical force at a depth of $0.4 D$ is termed $V_{\max }$. Following pipe embedment, the vertical force was reduced to $0.6 V_{\max }$, before the pipe was moved laterally under displacement control. The vertical force was maintained as $0.6 V_{\max }$ during the simulation of lateral buckling.

The element size around the pipe was selected as $0.05 \mathrm{D}$ in all analyses. In simulating this plane strain problem with a 3D CEL model, the thickness of soil slice normal to the pipe axis had negligible effect. As such, a plane strain slice of only one element thick was adopted. The penetration stage was mimicked by all three methods, but only CEL and RITSS were used to reproduce the lateral buckling stage. The buckling stage was not modelled by the EALE method since the current version of the code does not support reduction of the vertical force to $0.6 V_{\max }$ after the penetration stage. The penetration resistance, $V$, during penetration and horizontal resistance, $H$, during buckling were normalised in terms of the pipe diameter and soil strength at the current depth of the pipe invert.

In the CEL analysis, both the penetration velocity during penetration and the horizontal velocity during lateral buckling were taken as $v=0.01 \mathrm{~m} / \mathrm{s}$. As shown in Figure 4, the penetration resistances from analyses with $v=0.01$ and $0.005 \mathrm{~m} / \mathrm{s}$ are similar until the prescribed vertical movement of $0.4 D$, which testifies that $v=0.01 \mathrm{~m} / \mathrm{s}$ is sufficiently slow to generate quasi-static response. In addition, the effect of the time step in the explicit integration scheme was investigated by performing an additional calculation where the time step automatically determined by Abaqus was scaled by a factor of 0.5. The penetration resistance-displacement curves in terms of the two time steps are also compared in Figure 4. Although the automatic time step is recommended by Daussault Systèmes (2012), the numerical fluctuation is reduced significantly using a scaling factor of 0.5 for the time step, at least in this problem, especially when pipe penetration depth is larger than $0.3 D$. A similar phenomenon was observed for horizontal resistance during lateral buckling. The numerical accuracy is improved with the application of a scaling factor, although the computational cost was approximately doubled. For the penetration stage, the cost using half the automatic time step was 3.8 times of that with automatic step, but nonetheless the reduced time step was used in following comparison with the RITSS and EALE analyses. 
As observed in Figure 5a, the penetration resistances from three different methods are located in a relatively narrow range, although the resistance predicted by CEL is, in an average sense, slightly lower than those from RITSS and EALE. The curves based on implicit solutions are also much smoother than that obtained from the explicit scheme, as expected. During the lateral buckling stage, with constant vertical force, the horizontal movement of the pipe is accompanied by downward vertical movement into the soil, as shown in Figure 5b. The horizontal resistances estimated by CEL and RITSS are in good agreement, but with CEL predicting marginally lower downward movement. In Abaqus-based RITSS analysis, the vertical pipe displacement during penetration or the horizontal pipe displacement during buckling was taken as $0.02 D$ for each incremental step. The mesh generation is conducted at the beginning of each step to avoid element distortion. The mesh, representing the soil domain, is shown in Figure 6a at a pipe lateral displacement of $u=0.4 D$. In contrast, the Eulerian mesh in the CEL analysis is fixed, but the Lagrangian material (pipe) and Eulerian material (clay) are allowed to flow through the Eulerian elements (see Figure 6b).

\subsection{Consolidation under a surface footing}

An impermeable circular rough footing with diameter of $D=1 \mathrm{~m}$ was subjected to a pressure loading ramped to $150 \mathrm{kPa}$ in a day, then the pressure was sustained for long-term consolidation underneath the footing. The soil top surface was free-draining. In order to facilitate comparisons with previous results, the effective stress-stress relationship was described by a linear elastic model with Young's modulus $E^{\prime}=500 \mathrm{kPa}$, Poisson's ratio $v^{\prime}=0.3, \gamma=19.6 \mathrm{kN} / \mathrm{m}^{3}, K_{0}=0.43$ and permeability $k=$ $0.1 \mathrm{~mm} /$ day $\left(1.16 \times 10^{-9} \mathrm{~m} / \mathrm{s}\right)$. The horizontal and vertical extensions of the soil were $6 D$ and $4 D$, respectively. The element size around the footing was $0.125 D$.

As shown in Figure 7a, the RITSS and EALE achieve excellent agreement for the entire loading and consolidation process:

(i) The immediate settlement induced by the one-day-loading is $0.128 \mathrm{~m}$. The loading phase was nearly undrained, with shear modulus

$$
G=\frac{E^{\prime}}{2\left(1+v^{\prime}\right)}=192.3 \mathrm{kPa}
$$

In the Boussinesq solution for rigid footing, the immediate settlement is

$$
w=0.5\left(1-v_{\text {undrained }}\right) F / G D
$$

where the Poisson's ratio under undrained conditions is 0.5 and $\mathrm{F}$ is the force applied on the circular footing. The settlement against pressure of $150 \mathrm{kPa}$ is thus $0.153 \mathrm{~m}$ by Eq. 2. The marginal divergence 
between numerical and analytical solutions is partially due to the finite depth of the soil region: the settlement is increased to $0.138 \mathrm{~m}$ when the depth of soil is changed from $4 D$ to $8 D$.

(ii) The settlement reaches the ultimate value of about $0.175 \mathrm{~m}$ after $\sim 10$ years. The normalised histories of settlement during consolidation phase are validated in Figure 7b, in which the consolidation time is normalised in terms of coefficient of consolidation. The coefficient of consolidation for elastic material was calculated as (Gourvenc and Randolph, 2012)

$$
c_{\mathrm{v}}=\frac{k E^{\prime}}{\gamma_{\mathrm{w}}} \frac{1-v^{\prime}}{\left(1+v^{\prime}\right)\left(1-2 v^{\prime}\right)}=7.8 \times 10^{-8} \mathrm{~m}^{2} / \mathrm{s}
$$

where $\gamma_{\mathrm{w}}$ is the unit weight of water. Both numerical settlements during consolidation are in agreement with the analytical solution by Booker and Small (1986).

\subsection{Free falling cone penetrometer}

The free falling cone penetrometer, which is used extensively offshore, is similar in geometry to a standard cone penetrometer, but it is dropped to penetrate into the soil with an initial impact velocity. The free falling cone is advantageous in terms of its simplicity for measuring the soil strength at shallow depth, although the deduced strength will be affected by the very high strain rates. In the present analyses the cone was assumed to be smooth, with a diameter $D=40 \mathrm{~mm}$, shaft length of 365 $\mathrm{mm}$ (i.e. excluding the cone tip), apex angle of $60^{\circ}$ and net mass of $0.5 \mathrm{~kg}$. The impact velocity at the soil surface was $10 \mathrm{~m} / \mathrm{s}$. The unit weight, undrained strength and rigidity index of the soil were assumed to be $\gamma=19.6 \mathrm{kN} / \mathrm{m}^{3}, s_{\mathrm{u}}=5 \mathrm{kPa}$ and $\mathrm{G} / \mathrm{s}_{\mathrm{u}}=67$, respectively. To purely consider the shear strength of the soil in analysis, the initial geostatic stresses were zero. Although soil strength in reality is rate-dependent, and also likely to exhibit softening as it is remoulded, constant soil strength was adopted here to facilitate comparison between the various numerical approaches; a more complex model would superpose additional effects from simulating rate dependency and softening, resulting in potentially greater divergence between the different analysis methods. The typical element size along the cone and shaft was $h=D / 8$ in analyses using RITSS and EALE, which was testified as sufficiently fine to achieve convergent results (Nazem et al., 2012). The element size ranged from $D / 48$ to $D / 8$ in the CEL analyses.

The relationship between the velocity and penetration depth of the cone tip is shown in Figure 8. The curves predicted by the RITSS and EALE approaches achieve good agreement. The cone velocity increases slightly during the initial stage of penetration due to the self-weight of the probe, and then reduces gradually until the cone comes to a halt at a penetration of $12.1 D$. Although the CEL analysis with element size $h=D / 8$ shows a similar trend, the final penetration depth is only $8.8 D, 27 \%$ shallower than that predicted by RITSS and EALE. If the element size is reduced to $D / 16, D / 24, D / 32$ 
and $D / 48$, the final penetration depth is increased successively to $9.8 D, 10.3 D, 10.7 D$ and $10.9 D$. Considering the heavy computational effort, no further mesh refinement was attempted. However, the final penetration depth obtained with a finer mesh is expected to be marginally larger than $10.9 D$. The time step automatically determined by Abaqus was adopted in the above CEL analyses. Additional calculations with a reduced time step (by a factor of 0.5 ) were conducted for typical element sizes $\mathrm{h}=\mathrm{D} / 16$ and $D / 32$. The responses obtained in terms of the two time steps were nearly identical, which suggests that the automatic time step is sufficiently small to ensure computational convergence for the specified element size.

\subsection{Discussion in terms of benchmark cases}

The performance of RITSS, EALE and CEL was compared through the above benchmark cases:

(i) In the two quasi-static problems (e.g. cone and pipeline cases), the load-displacement curves provided by the CEL show good agreement with those by the RITSS and EALE, although the CEL results exhibit numerical oscillation typical of solutions based on an explicit scheme. For the dynamic analysis of a free falling penetrometer, the final penetration depth obtained with CEL increases significantly with reduction of element size. One possible reason is that the contact interface detected in the CEL analysis is not expected to be as accurate as that in Lagrangian-based approaches since it is determined through the volume fraction of each material in each element.

(ii) The EALE method employed in this work has been implemented in an in-house FE program tailored to geomechanics problems. Having access to the source code is advantageous as it allows modifications to be coded by the user. The interface between the soil and a structural element is modelled by the Node-To-Segment method in contact mechanics, however, discontinuity in contact forces usually occurs as a node moves from one segment to another, causing oscillation in force vectors. To avoid this, higher order contact or formulation based on non-uniform rational B-spline needs to be employed in the future.

(iii) In the RITSS analysis of the dynamic case (e.g. free falling cone), the time step needs to be selected sufficiently small at very early stage of penetration, since a few soil elements around the high-speed probe undergo sudden and severe deformations. If the impact velocity of penetrometer is increased further, it is difficult for RITSS to complete the calculation. The efficiency of RITSS is also limited in high-speed dynamic problems, due to the essence of implicit calculation in each Lagrangian step with sufficiently small step size. The FE approach or material point method based on explicit scheme may be better option.

(iv) The RITSS and EALE agree very well with each other in all cases, suggesting that different convection strategies adopted in the Eulerian phase provide similar accuracy. However, both RITSS 
and EALE are coded as in-house programs, despite the procedures of implementation being publicly available in Wang et al. (2010a) and Nazem et al. (2006), respectively. In contrast, the CEL approach is an option in a commercially available code, and while user expertise is required to perform analyses as intended (see the discussions on critical time step and velocity in quasi-static simulations above), no programming is necessary. The CEL approach available in Abaqus has been shown to be versatile, accurate and well suited to geotechnical problems with the exception of diffusion. Implicit approaches lend themselves to consolidation problems, which is outside the capabilities of the commercially available explicit code.

\section{CONCLUSIONS}

The performance of three numerical analysis approaches catering for large deformations, RITSS, EALE and CEL, was compared using four prominent geotechnical problems, i.e. a standard smoothsided cone penetrating into clay, pipeline penetration and lateral movement in clay, consolidation of elastic material under a surface footing, and a free falling cone penetrometer in clay.

As no exact solutions are available for the example problems, relative comparisons are drawn. The three methods yield similar results for the quasi-static penetration problems. In the CEL analysis the penetration velocity and critical time step need to be selected carefully, while the re-meshing interval requires attention in the two selected implicit methods. The footing settlements in the consolidation analysis predicted by the EALE and RITSS are similar. For the dynamic example, the result obtained with the CEL show dependency on element size (even very fine mesh was used in the region concerned) and differs from those predicted with the EALE and RITSS. The exact solution for this problem is not known.

Though this contribution illustrates that large deformation geotechnical problems can be solved through different approaches, each giving reasonable results despite the differences in solution algorithm, element type and mapping, perhaps the most obvious difference lies in the limitations of the three techniques. The EALE and RITSS predict close results in all cases, but both programs are in-house codes. CEL, on the other hand, is part of a commercially available software and accommodates boundary value problems with more complex geometries that challenge the implicit schemes. Consolidation analysis is outside the capabilities of the commercially available explicit code considered here.

\section{ACKNOWLEDGEMENTS}

This work forms part of the activities of the Australian Research Council (ARC) Centre of Excellence for Geotechnical Science and Engineering. This project has received additional support from the ARC 
programs (DP120102987, DP110101033). The second author is the recipient of an ARC Postdoctoral Fellowship (DP110101603). The authors are grateful for these supports.

\section{REFERENCES}

Andresen, L. and Khoa, H.D.V. (2013). LDFE analysis of installation effects for offshore anchors and foundations. Proceedings of International Conference on Installation Effects in Geotechnical Engineering, 162-168.

Benson, D.J. (1989). An efficient, accurate and simple ALE method for nonlinear finite element programs, Computer Methods in Applied Mechanics and Engineering, 72, 305-350.

Benson, D.J. (1992). Computational methods in Lagrangian and Eulerian hydrocodes. Computer Methods in Applied Mechanics and Engineering, 99, 235-394.

Beuth, L., Więckowski, Z. and Vermeer, P.A. (2011). Solution of quasi-static large-strain problems by the material point method. International Journal for Numerical and Analytical Methods in Geomechanics, 35(13), 1451-1465.

Booker, J.R. and Small, J.C. (1986). The behaviour of an impermeable flexible raft on a deep layer of consolidating soil. International Journal for Numerical and Analytical Methods in Geomechanics, 10(3), 311-327.

Boroomand, B. and Zienkiewicz, O.C. (1997). An improved REP recovery and the effectivity robustness test. International Journal for Numerical Methods in Engineering, 40, 3247-3277.

Carter, J.P. and Balaam, N.P. (1995). AFENA User Manual 5.0. Geotechnical Research Centre, The University of Sydney, Sydney, Australia.

Chatterjee, S., White, D.J. and Randolph, M.F. (2012). Numerical simulations of pipe-soil interaction during large lateral movements on clay. Géotechnique, 62(8), 693-705.

Chen, Z., Tho, K.K., Leung, C.F. and Chow, Y.K. (2013). Influence of overburden pressure and soil rigidity on uplift behavior of square plate anchor in uniform clay. Computers and Geotechnics, 52, 71-81.

Dassault Systèmes (2012). Abaqus User’s Manual, Version 6.12.

Gourvenec, S. and Randolph, M.F. (2010). Consolidation beneath circular skirted foundations. International Journal of Geomechanics, 10, 22-29.

Hu, P., Wang, D., Cassidy, M.J. and Stanier, S.A. (2014). Predicting the resistance profile of a spudcan penetrating sand overlying clay. Canadian Geotechnical Journal, 51, 1151-1164.

Hu, Y. and Randolph, M.F. (1998a). A practical numerical approach for large deformation problems in soil. International Journal for Numerical and Analytical Methods in Geomechanics, 22(5), 327-350.

Hu, Y. and Randolph, M.F. (1998b). H-adaptive FE analysis of elasto-plastic non-homogeneous soil with large deformation. Computers and Geotechnics, 23(1), 61-83.

Hu, Y., Randolph, M.F. and Watson, P.G. (1999). Bearing response of skirted foundations on non-homogeneous soil, Journal of Geotechnical and Geoenvironmental Engineering, 125(12), 924-935.

Hossain, M.S., Hu, Y., Randolph, M.F. and White, D.J. (2005). Limiting cavity depth for spudcan foundations penetrating clay. Géotechnique, 55(9), 679-690.

Hossain, M.S. and Randolph, M.F. (2010). Deep-penetrating spudcan foundations on layered clays: numerical analysis. Géotechnique, 60(3), 171-184.

Liyanapathirana, D.S. (2009). Arbitrary Lagrangian Eulerian based finite element analysis of cone penetration in soft clay, Computers and Geotechnics, 36(5), 851-860.

Lu, Q., Randolph, M.F., Hu, Y. and Bugarski, I.C. (2004). A numerical study of cone penetration in clay. Géotechnique, 54(4), 257-267.

Nazem, M., Sheng, D. and Carter, J.P. (2006). Stress integration and mesh refinement in numerical solutions to large deformations in geomechanics, International Journal for Numerical Methods in Engineering, 65, 1002-1027.

Nazem, M., Sheng, D., Carter, J.P. and Sloan, S.W. (2008). Arbitrary-Lagrangian-Eulerian method for large-deformation consolidation problems in geomechanics, International Journal for Numerical and Analytical Methods in Geomechanics, 32, 1023-1050.

Nazem, M., Carter, J.P. and Airey, D.W. (2009a). Arbitrary Lagrangian-Eulerian Method for dynamic analysis of Geotechnical Problems, Computers and Geotechnics, 36 (4), 549-557. 
Nazem, M., Carter, J.P., Sheng, D. and Sloan, S.W. (2009b). Alternative stress-integration schemes for large-deformation problems of solid mechanics. Finite Elements in Analysis and Design, 45(12), 934-943.

Nazem, M., Carter, J.P., Airey, D.W. and Chow, S.H. (2012). Dynamic analysis of a smooth penetrometer free-falling into uniform clay, Géotechnique, 62 (10), 893-905.

Pucker, T., Bienen, B. and Henke, S. (2013). CPT based prediction of foundation penetration in siliceous sand. Applied Ocean Research, 41, 9-18.

Pucker, T. and Grabe, J. (2012): Numerical simulation of the installation process of full displacement piles. Computers and Geotechnics, 45, 93-106.

Qiu, G. and Grabe, J. (2012). Numerical investigation of bearing capacity due to spudcan penetration in sand overlying clay. Canadian Geotechnical Journal, 49(12), 1393-1407.

Qiu, G. and Henke, S. (2011). Controlled installation of spudcan foundations on loose sand overlying weak clay. Marine Structures, 24(4): 528-550.

Sabetamal, H., Nazem, M., Carter, J.P. and Sloan, S.W. (2014). Large deformation dynamic analysis of saturated porous media with applications to penetration problems, Computers and Geotechnics, 55, 117-131.

Sheng, D., Nazem, M. and Carter, J.P. (2009). Some computational aspects for solving deep penetration problems in geomechanics. Computational Mechanics, 44(4), 549-561.

Song, Z., Hu, Y. and Randolph, M.F. (2008). Numerical simulation of vertical pullout of plate anchors in clay. Journal of Geotechnical and Geoenvironmental Engineering, 134(6), 866-875.

Sulsky, D., Zhou S. and Schreyer H.L. (1995). Application of a particle-in-cell method to solid mechanics. Computer Physics Communications, 87, 235-252.

Susila, E. and Hryciw, R.D. (2003). Large displacement FEM modelling of the cone penetration test (CPT) in normally consolidated sand. International Journal for Numerical and Analytical Methods in Geomechanics, 27(7), 585-602.

Teh, C.I. and Houlsby, G.T. (1991). An analytical study of the cone penetration test in clay. Géotechnique, 41(1), 17-34.

Tho, K.K., Leung, C.F., Chow, Y.K., and Swaddiwudhipong, S. (2012). Eulerian finite element technique for analysis of jack-up spudcan penetration. International Journal of Geomechanics, 12 (1), 64-73.

Tho, K.K., Leung, C.F., Chow, Y.K., and Swaddiwudhipong, S. (2013). Eulerian finite element simulation of spudcanpile interaction. Canadian Geotechnical Journal, 50(6), 595-608.

Tian, Y., Cassidy, M.J., Randolph, M.F., Wang, D. and Gaudin, C. (2014a). A simple implementation of RITSS and its application in large deformation analysis. Computers and Geotechnics, 56, 160-167.

Tian, Y., Gaudin, C., and Cassidy, M.J. (2014b). Improving plate anchor design with a keying flap. Journal of Geotechnical and Geoenvironmental Engineering, 140(5), 04014009.

Tian, Y., Gaudin, C. Randolph, M.F. and Cassidy, M.J. (2014c) The influence of padeye offset on the bearing capacity of three dimensional plate anchors. Canadian Geotechnical Journal, DOI: 10.1139/cgj-2014-0120.

van den Berg, P., deBorst, R. and Huetink, H. (1996). An Eulerian finite element model for penetration in layered soil. International Journal for Numerical and Analytical Methods in Geomechanics, 20(12), 865-886.

Walker, J. and Yu, H.S. (2010). Analysis of cone penetration test in layered clay. Géotechnique, 60(12), 939-948.

Walker, J. and Yu, H.S. (2006). Adaptive finite element analysis of cone penetration in clay. ACTA Geotechnica, 1(1), 43-57.

Wang, D., Hu, Y. and Randolph, M.F. (2010a). Three-dimensional large deformation finite element analysis of plate anchors in uniform clay. Journal of Geotechnical and Geoenvironmental Engineering, 136(2), 355-365.

Wang, D., Hu, Y. and Randolph, M.F. (2011) Keying of rectangular plate anchors in normally consolidated clays. Journal of Geotechnical and Geoenvironmental Engineering, 137(12), 1244-1253.

Wang, D., Gaudin, C. and Randolph, M.F. (2013a). Large deformation finite element analysis investigating the performance of anchor keying flap. Ocean Engineering, 59(1), 107-116.

Wang, D., Merifield, R.S. and Gaudin, C. (2013b). Uplift behaviour of helical anchors in clay. Canadian Geotechnical Journal, 50, 575-584.

Wang, D. and O’Loughlin, C.D. (2014). Numerical study of pull-out capacities of dynamically embedded plate anchors. Canadian Geotechnical Journal, 51(11), 1263-1272.

Wang, D., Randolph, M.F. and White D.J. (2013c). A dynamic large deformation finite element method based on mesh regeneration. Computers and Geotechnics, 54, 192-201. 
Wang, D., White, D.J. and Randolph, M.F. (2010b). Large deformation finite element analysis of pipe penetration and large-amplitude lateral displacement. Canadian Geotechnical Journal, 47(8): 842-856.

Yi, J.T., Lee, F.H., Goh, S.H., Zhang, X.Y. and Wu, J.F. (2012). Eulerian finite element analysis of excess pore pressure generated by spudcan installation into soft clay. Computers and Geotechnics, 42, 157-170.

Yu, L., Hu, Y., Liu, J., Randolph, M.F. and Kong, X. (2012). Numerical study of spudcan penetration in loose sand overlying clay. Computers and Geotechnics, 46, 1-12.

Zhou, H., and Randolph, M.F. (2009). Resistance of full-flow penetrometers in rate-dependent and strain-softening clay. Géotechnique, 59(2), 79-86.

Zienkiewicz, O.C. and Zhu, J.Z. (1993). The superconvergent patch recovery and a posteriori error estimates. Part 1: The recovery technique. International Journal for Numerical Methods in Engineering, 33, 1331-1364.

\section{APPENDIX A: MATHEMATIC FRAMEWORK OF RITSS}

The governing equations of the dynamic total stress analysis are taken as example. The incremental displacements are calculated by satisfying the principle of virtual work:

$$
\begin{aligned}
& \sum_{k}\left(-\int_{V_{k}} \sigma_{i j} \delta \varepsilon_{i j} d V_{k}-\int_{V_{k}} \delta u_{i} \rho \ddot{u}_{i} d V_{k}-\int_{V_{k}} \delta u_{i} c \dot{u}_{i} d V_{k}+\int_{V_{k}} \delta u_{i} b_{i} d V_{k}+\int_{S_{k}} \delta u_{i} q_{i} d S_{k}\right) \\
& +\int_{S_{C}}\left(t_{\mathrm{N}} \delta g_{\mathrm{N}}+t_{\mathrm{T}} \delta g_{\mathrm{T}}\right) d S_{C}=0
\end{aligned}
$$

where $k$ is the total number of bodies in contact, $\sigma_{i j}$ denotes the Cauchy stress tensor, $\delta \varepsilon_{i j}$ is the variation of strain due to virtual displacement, $u_{i}$ represents material displacements, $\delta u_{i}$ is virtual displacement, $\rho$ and $c$ are the material density and damping, $b_{i}$ is the body force, $q_{i}$ is the surface load acting on area $S_{k}$ of volume $V_{k}$, and a superimposed dot represents the time derivative of a variable. $\delta g_{\mathrm{N}}$ and $\delta g_{\mathrm{T}}$ are the virtual normal and tangential gap displacements, $t_{\mathrm{N}}$ and $t_{\mathrm{T}}$ denote the normal and tangential tractions at the contact surface $S_{c}$. Equation 1 is solved using standard UL algorithm, and then the deformed soil is remeshed. The stresses at each new integration point are then approximated as

$$
\hat{\sigma}_{i j}=\boldsymbol{P} \boldsymbol{a}_{i j}
$$

where the polynomial expansion $\boldsymbol{P}=\left(1, x_{1}, x_{2}, x_{1}{ }^{2}, x_{2}{ }^{2}, x_{1} x_{2}\right)$ for $2 \mathrm{D}$ problems, $x_{1}$ and $x_{2}$ representing the coordinates of the integration point; and $\boldsymbol{a}_{i j}$ is a finite number of unknown parameters, which is obtained through particular mapping technique adopted. The velocities and accelerations at each new node are interpolated as

$$
\begin{aligned}
& \hat{\dot{u}}_{i}=N \dot{u}_{i} \\
& \hat{\ddot{u}}_{i}=N \ddot{u}_{i}
\end{aligned}
$$

where $\boldsymbol{N}$ is the shape function of triangle or quadrilateral element. The governing equations are satisfied approximately at the beginning of next step 


$$
\begin{aligned}
& \sum_{k}\left(-\int_{V_{k}} \hat{\sigma}_{i j} \delta \varepsilon_{i j} d V_{k}-\int_{V_{k}} \delta u_{i} \rho \hat{\ddot{u}}_{i} d V_{k}-\int_{V_{k}} \delta u_{i} c \hat{\dot{u}}_{i} d V_{k}+\int_{V_{k}} \delta u_{i} b_{i} d V_{k}+\int_{S_{k}} \delta u_{i} q_{i} d S_{k}\right) \\
& +\int_{S_{C}}\left(\hat{t}_{\mathrm{N}} \delta g_{\mathrm{N}}+\hat{t}_{\mathrm{T}} \delta g_{\mathrm{T}}\right) d S_{c} \approx 0
\end{aligned}
$$

The contact tractions, $\hat{t}_{\mathrm{N}}$ and $\hat{t}_{\mathrm{T}}$, are not mapped, instead, they are derived by matching the mapped stresses, velocities and acceleration in the governing equations.

\section{APPENDIX B: MATHEMATIC FRAMEWORK OF EALE}

The EALE is based on the operator split technique in which the analysis is performed in two phases: an UL phase followed by an Eulerian phase. Governing equations, Eq. A1, are solved in the UL phase. In the Eulerian phase, the mesh is refined without changing the topology of the domain, but by changing the spatial location of nodes. After mesh refinement, all field variables at nodes and integration points need to be mapped from the distorted mesh to the new mesh. This mapping is performed by the convection equation according to

$$
\dot{f}^{r}=\dot{f}+\left(\dot{u}_{i}-\dot{u}_{i}^{r}\right) \frac{\partial f}{\partial x_{i}}
$$

where $\dot{f}^{r}$ and $\dot{f}$ denote the time derivative of an arbitrary field variable with respect to the mesh and material coordinates respectively, $\dot{u}_{i}$ is the material velocity, and $\dot{u}_{i}^{r}$ represents the mesh velocity.

To describe the contact at the interface between two bodies, the penalty method is used to formulate the constitutive relations in tangential and normal directions. The normal contact in the penalty method is described by

$$
t_{\mathrm{N}}=\varepsilon_{\mathrm{N}} g_{\mathrm{N}}
$$

where $\varepsilon \mathrm{N}$ is a penalty parameter for the normal contact. In the tangential direction the so-called 'stick and slip' strategy is used. Based on this concept, the relative tangential velocity between the bodies, $\dot{g}_{\mathrm{T}}$, is split into two a stick part $\dot{g}_{\mathrm{T}}^{\text {st }}$ and a slip part $\dot{g}_{\mathrm{T}}^{\text {sl }}$, as in the following rate form

$$
\dot{g}_{\mathrm{T}}=\dot{g}_{\mathrm{T}}^{\mathrm{st}}+\dot{g}_{\mathrm{T}}^{\mathrm{sl}}
$$

The tangential component of traction is then obtained by

$$
t_{\mathrm{T}}=\varepsilon_{\mathrm{T}} g_{\mathrm{T}}^{\mathrm{st}}
$$


where $\varepsilon_{\mathrm{T}}$ is a penalty parameter in tangential direction. A slip criterion function is then defined by writing the classical Coulomb friction criterion in the following form

$$
f_{s}\left(t_{\mathrm{N}}, t_{\mathrm{T}}\right)=\left\|t_{\mathrm{T}}\right\|-\mu t_{\mathrm{N}} \leq 0
$$

where $\mu$ is the friction coefficient.

\section{APPENDIX C: MATHEMATIC FRAMEWORK OF CEL}

The mathematic framework of CEL was detailed by Benson (1992), with a brief summary presented in this appendix. The material flow is obtained using the operator split technique

$$
\begin{aligned}
& \dot{f}=S \\
& \dot{f}+\nabla \cdot \Phi=0
\end{aligned}
$$

where $f$ represents the field variable, $\Phi$ is the flux function, and $S$ is the source term.

Equation C1, for the Lagrangian phase, is essentially identical to traditional expression (Eq. A1). The governing equations are solved using an explicit integration scheme, the central difference method. For Eq. C2, the deformed mesh is moved to the original mesh, and the volume of materials transported between adjacent elements is calculated. The solutions from Equation C1 are then mapped to the new integration point using first-order or second-order advection. For second-order advection used in this study, a linear distribution of the field variable is assumed in each old element expressed as

$$
f=s\left(v o l-v_{i}\right)+f_{i}
$$

where vol is the volume coordinate, $v l_{i}$ is the volume coordinate of the old integration point $i, f_{j}$ is the volume-averaged field variable at the old integration point $i$, and $s$ is the slope of the interpolation function. The linear distribution in the element is limited by changing slope $s$ until the mapped variables in the element are within the range decided by the values at the deformed integration points, i.e. the monotonicity is remained.

The boundary of each material is computed through the volume fractions and the interface reconstruction algorithm within an element. The strain is unique for all materials accommodated by an Eulerian element. Mean strain rate mixture theory is used to tackle the contact between Eulerian materials. The contact between the Lagrangian and Eulerian material is simulated using the penalty method. 
Table 1 Differences of three approaches

\begin{tabular}{|l|l|l|l|}
\hline & RITSS & EALE & CEL \\
\hline Integration scheme & Implicit & Implicit & Explicit \\
\hline Elements & Quadratic & Quadratic, Quartic, Quintic & Linear \\
\hline Implementation & 2D, 3D & 2D & $3 \mathrm{D}$ \\
\hline Meshing & $\begin{array}{l}\text { Periodic mesh regeneration in } \\
\text { global or local region }\end{array}$ & $\begin{array}{l}\text { Mesh refinement by adjusting } \\
\text { the location of nodal points }\end{array}$ & Mesh fixed in space \\
\hline $\begin{array}{l}\text { Mapping of field } \\
\text { variables }\end{array}$ & Interpolation & ALE convection equation & First or second order \\
\hline $\begin{array}{l}\text { Cost of } \\
\text { Lagrangian phase }\end{array}$ & Heavy & Heavy & Moderate \\
\hline $\begin{array}{l}\text { Cost of Eulerian } \\
\text { phase }\end{array}$ & Minimal & Minimal & Heavy \\
\hline
\end{tabular}




\begin{tabular}{|l|l|l|l|}
\hline Applications & Static, dynamic, consolidation & $\begin{array}{l}\text { Static, dynamic, } \\
\text { consolidation, dynamic } \\
\text { consolidation }\end{array}$ & Quasi-static, dynamic \\
\hline User-friendliness & $\begin{array}{l}\text { Commercial pre- and post- } \\
\text { processors, but requires script } \\
\text { programs to control processors }\end{array}$ & $\begin{array}{l}\text { In-house pre- and post- } \\
\text { processors }\end{array}$ & $\begin{array}{l}\text { Commercially available, } \\
\text { graphical interface } \\
\text { available }\end{array}$ \\
\hline
\end{tabular}

Table 2 Static, consolidation and dynamic benchmark cases

\begin{tabular}{|l|l|l|l|l|l|l|}
\hline Case & Problem & Type & Analysis type & Soil model & Contact & Approaches \\
\hline 1 & Cone penetration & Axisymmetric & Total stress, static & von Mises & Smooth & $\begin{array}{l}\text { RITSS, } \\
\text { EALE, CEL }\end{array}$ \\
\hline 2 & $\begin{array}{l}\text { Buckling of a } \\
\text { pipeline }\end{array}$ & Plane strain & Total stress, static & Tresca & Frictional & $\begin{array}{l}\text { RITSS, } \\
\text { EALE }, \text { CEL }\end{array}$ \\
\hline 3 & $\begin{array}{l}\text { Consolidation } \\
\text { under a surface } \\
\text { footing }\end{array}$ & Axisymmetric & Coupled & Linear elastic & N/A & $\begin{array}{l}\text { RITSS, } \\
\text { EALE }\end{array}$ \\
\hline 4 & $\begin{array}{l}\text { Penetration of free- } \\
\text { falling cone } \\
\text { penetrometer }\end{array}$ & Axisymmetric & $\begin{array}{l}\text { Total stress, } \\
\text { dynamic }\end{array}$ & Tresca & & Smooth \\
\hline
\end{tabular}

${ }^{*}$ Vertical penetration stage only

\section{FIGURE CAPTIONS}

Figure 1 Finite element meshes used in cone penetration tests

Figure 2 Resistance-displacement curves for cone penetration in weightless soil

Figure 3 Influence of penetration velocity on cone tip resistance in CEL analysis

Figure 4 Effects of penetration rate and time step in CEL analysis

Figure 5 Response of pipe during penetration and lateral buckling

Figure 6 Meshes at lateral displacement $u=0.4 D$

Figure 7 Settlement underneath circular footing

Figure 8 Dynamic penetration of free falling cone 


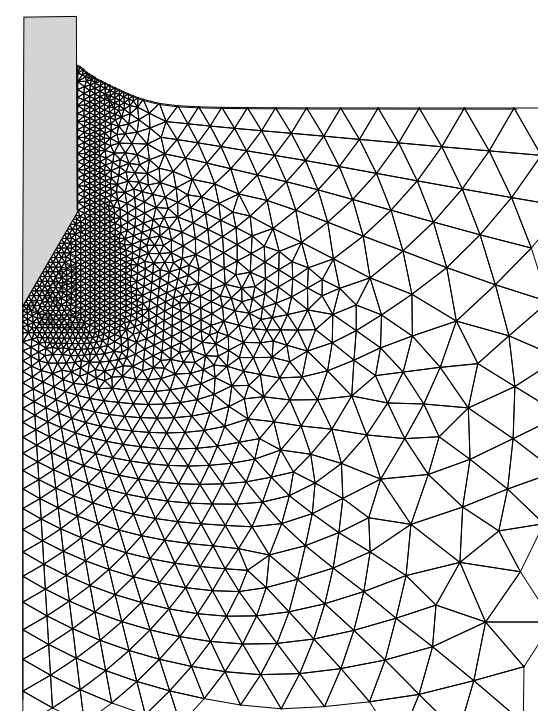

(a) RITSS, cone tip depth $1.8 \mathrm{D}$

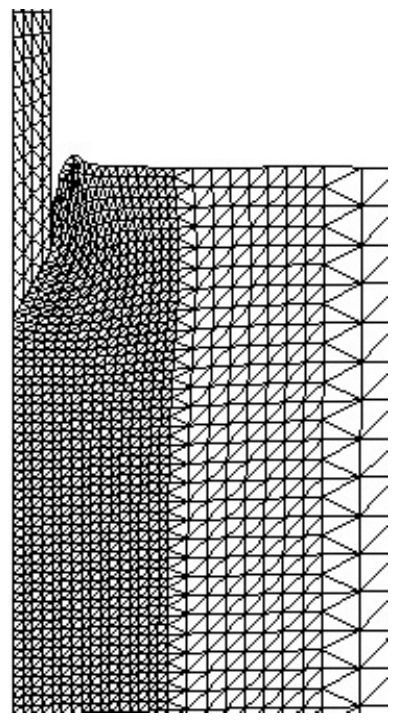

(b) EALE, cone tip depth $1.8 D$

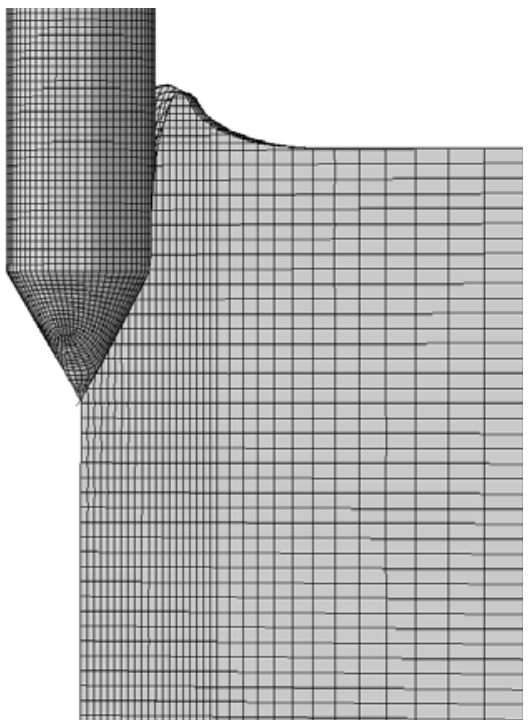

(c) CEL, cone tip depth $1.7 \mathrm{D}$

Figure 1 Finite element meshes used in cone penetration tests 


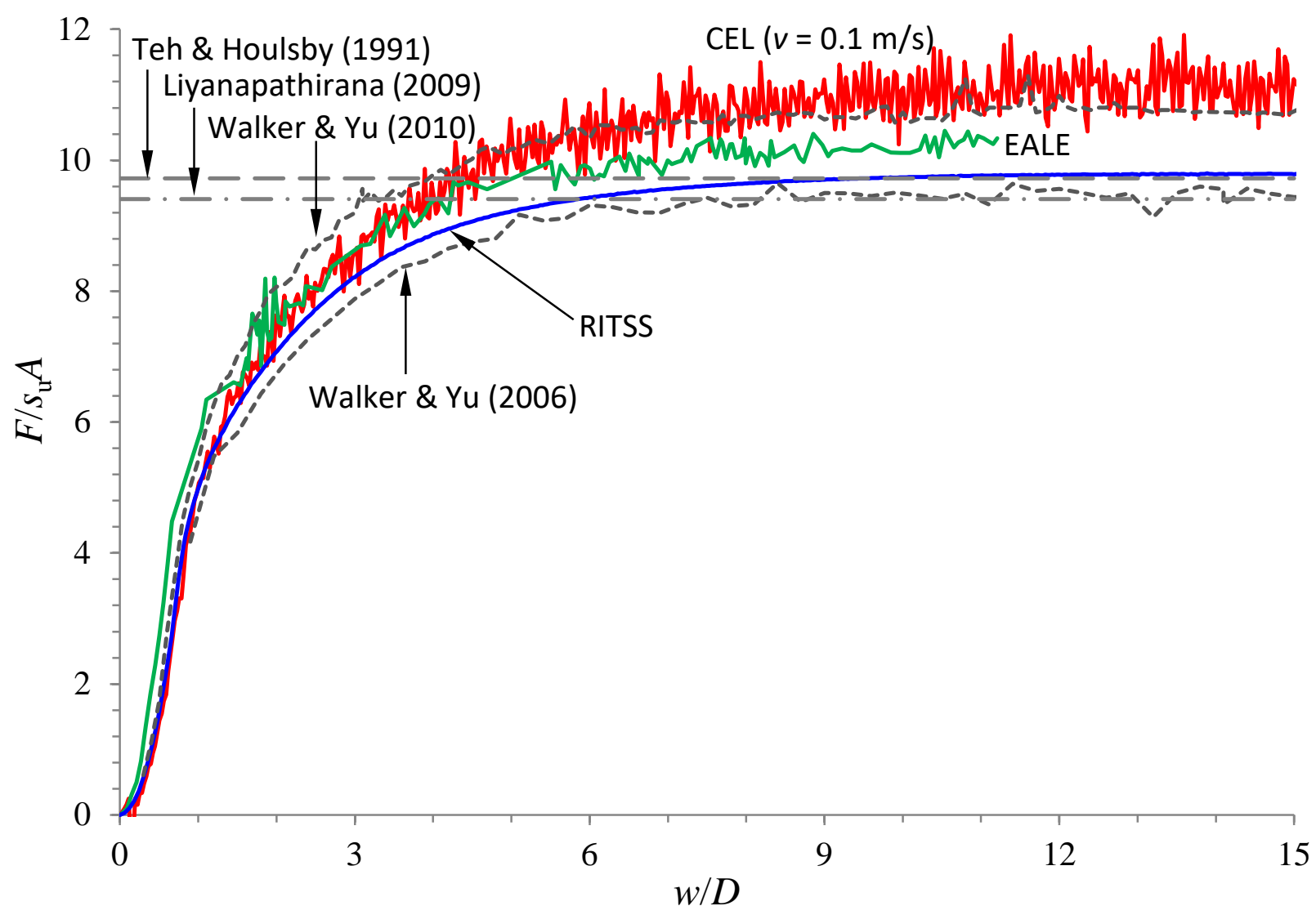

Figure 2 Resistance-displacement curves for cone penetration in weightless soil 


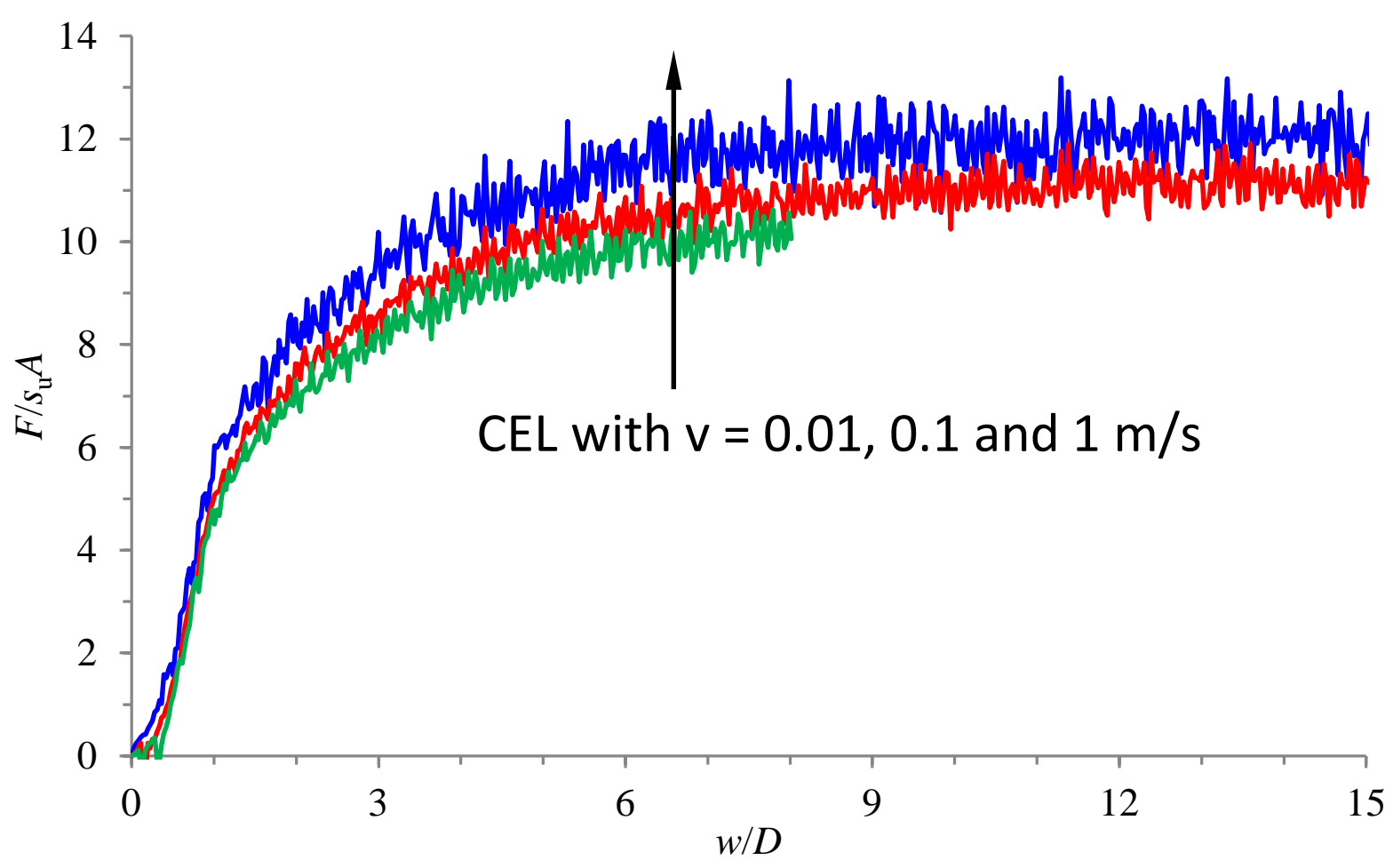

Figure 3 Influence of penetration velocity on cone tip resistance in CEL analysis

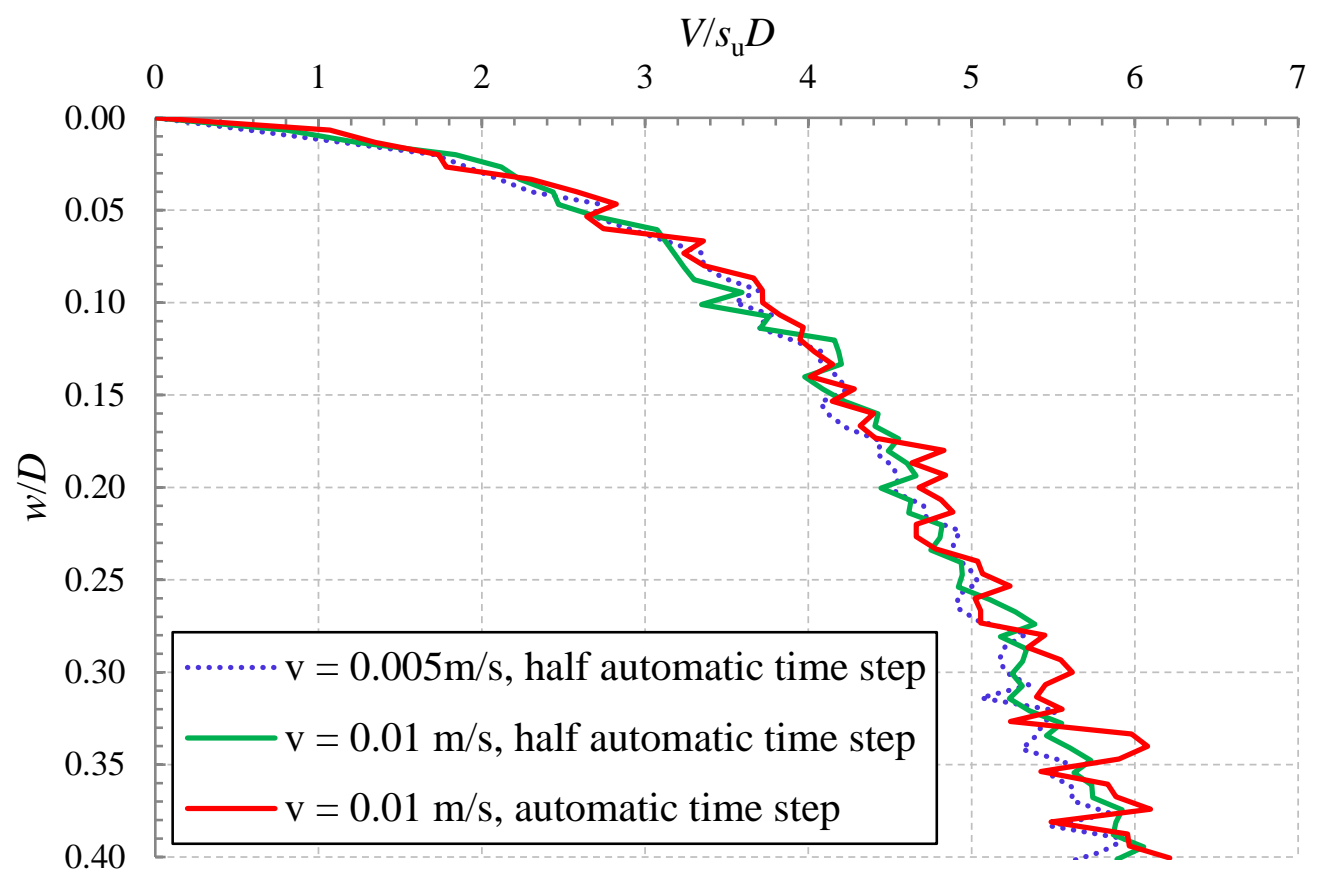

Figure 4 Effects of penetration rate and time step in CEL analysis 


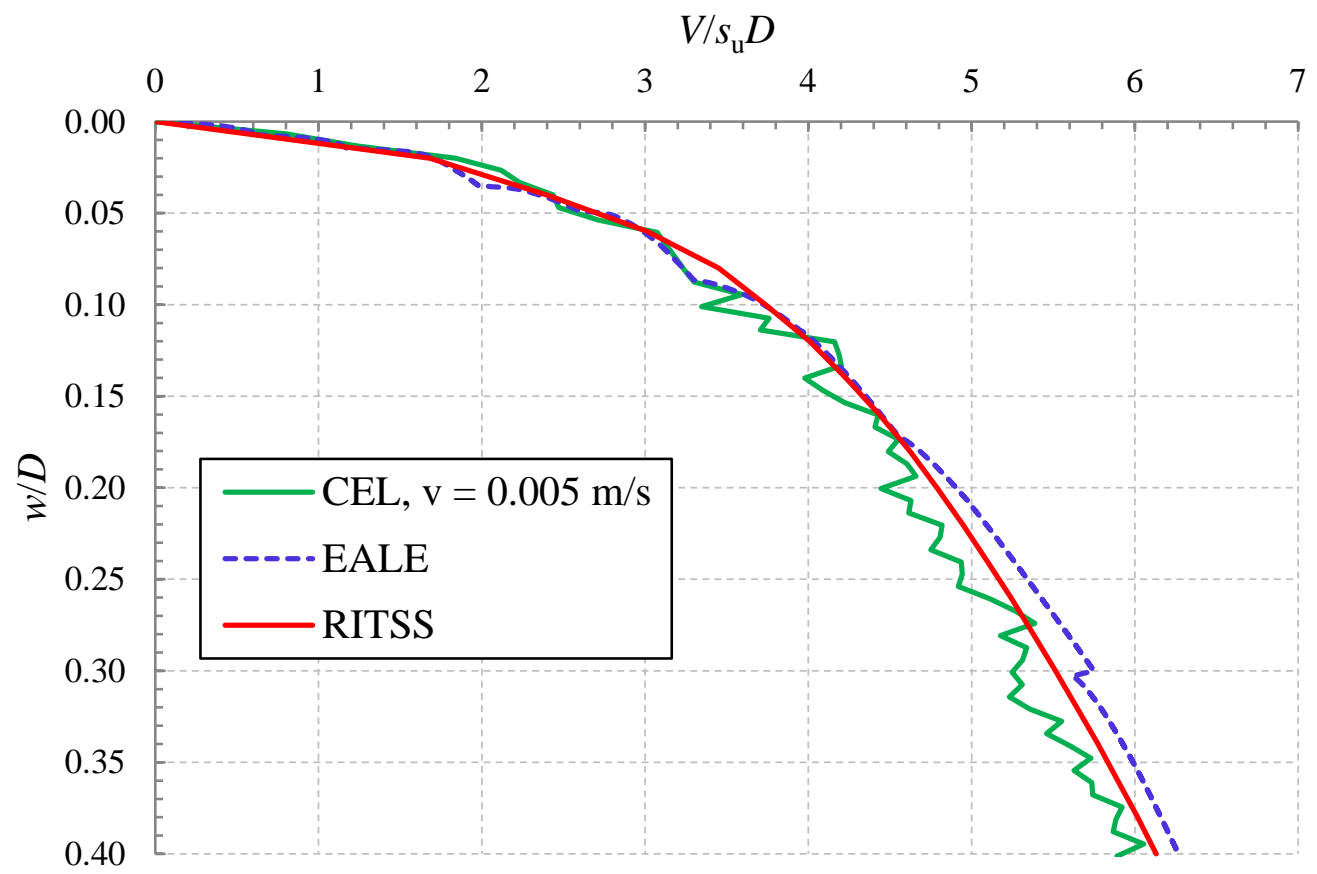

(a) Load-displacement curve during penetration 


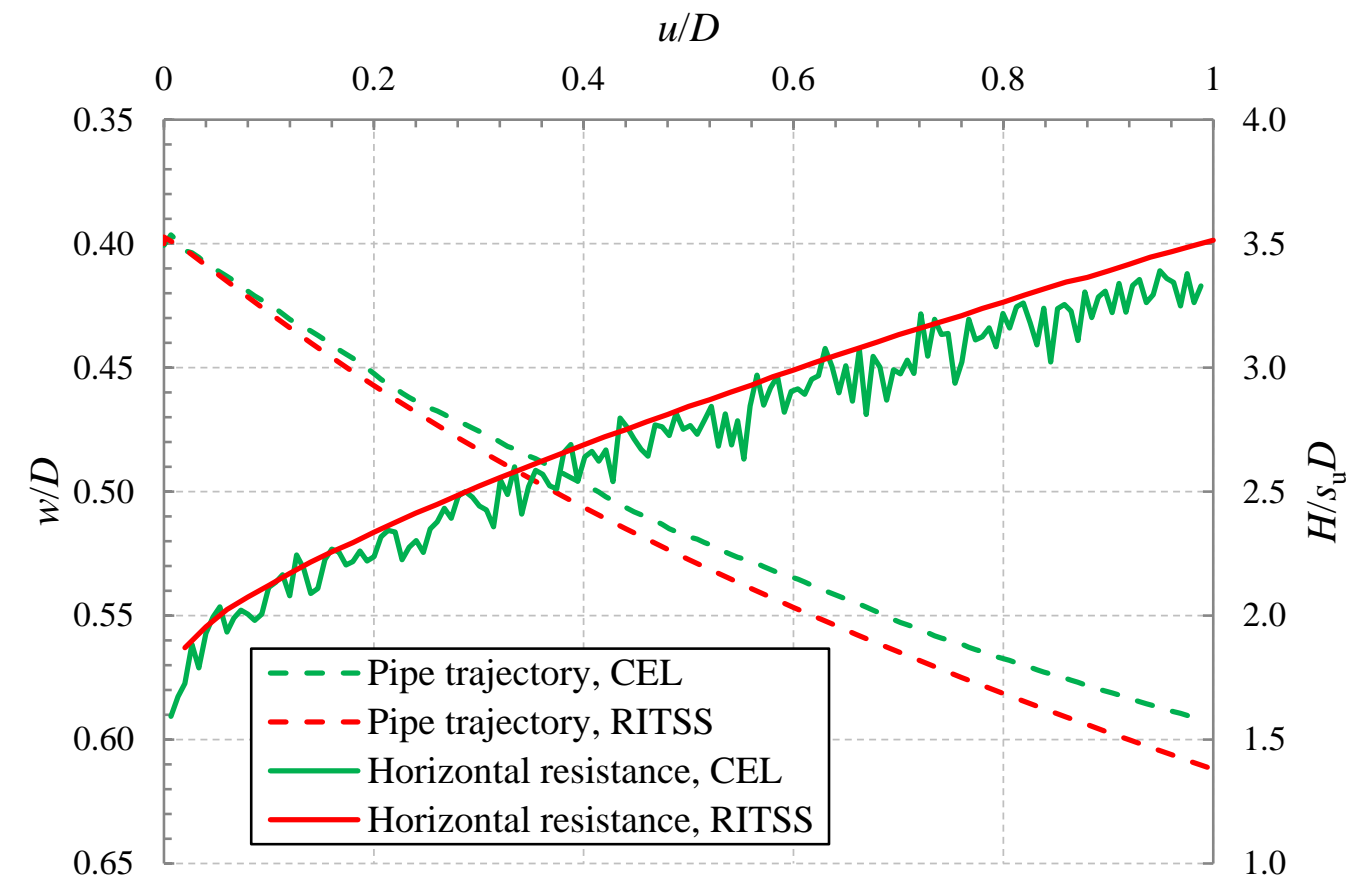

(b) Horizontal resistance and pipe trajectory during lateral buckling

Figure 5 Response of pipe during penetration and lateral buckling

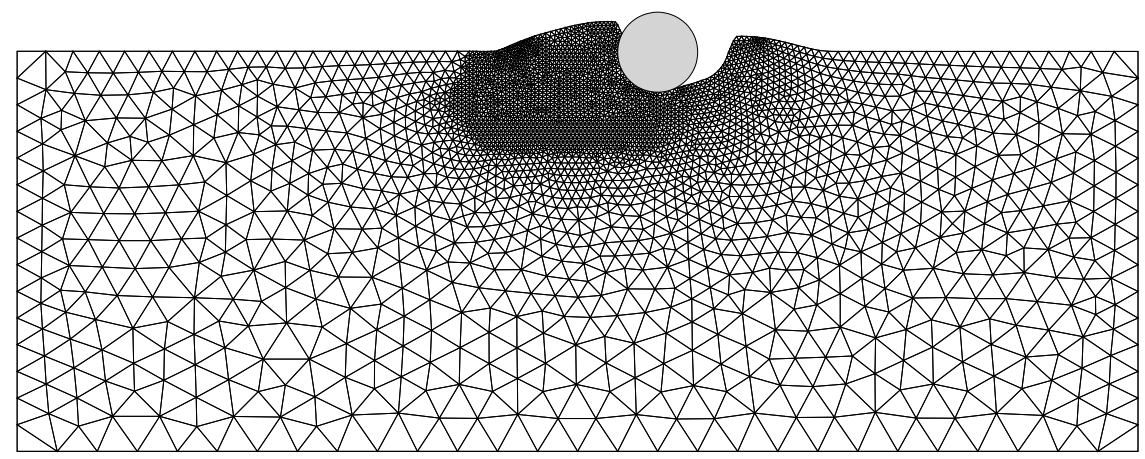

(a) RITSS 


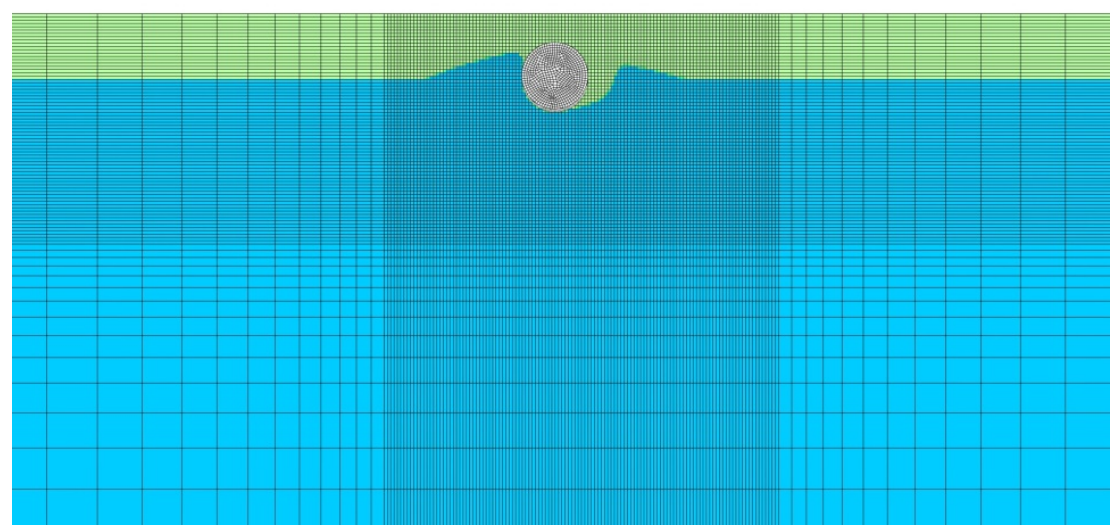

(b) CEL (dark representing soil material, light void)

Figure 6 Meshes at lateral displacement $u=0.4 D$

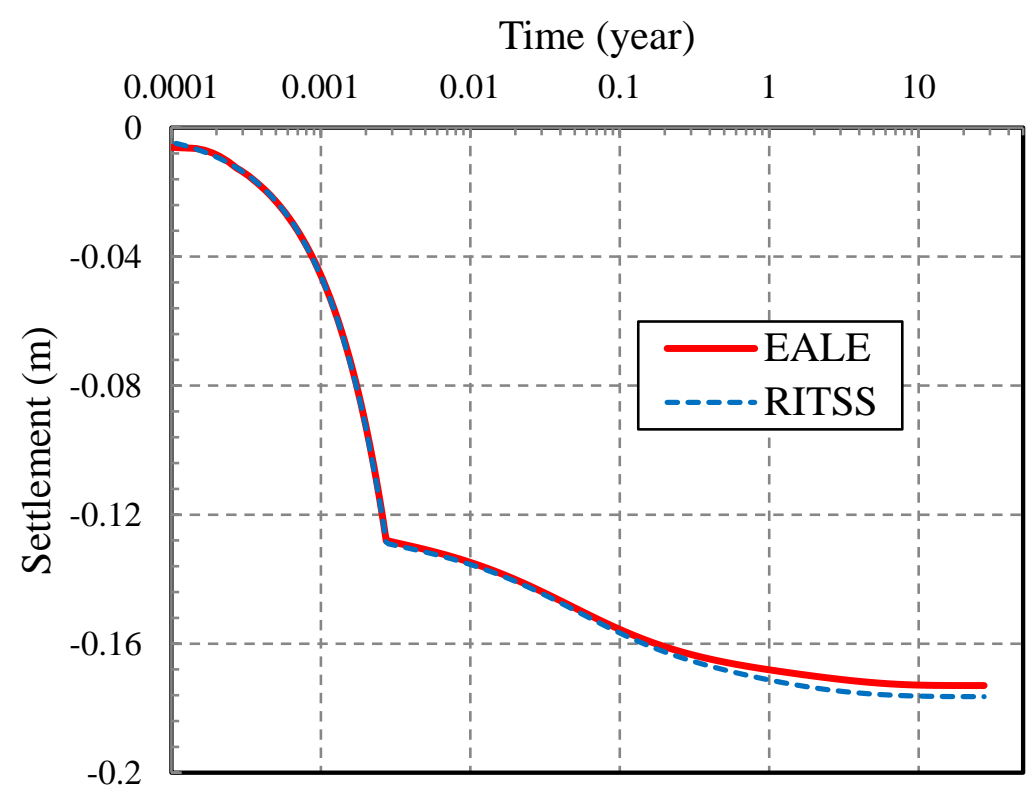

(a) Dimensional results 


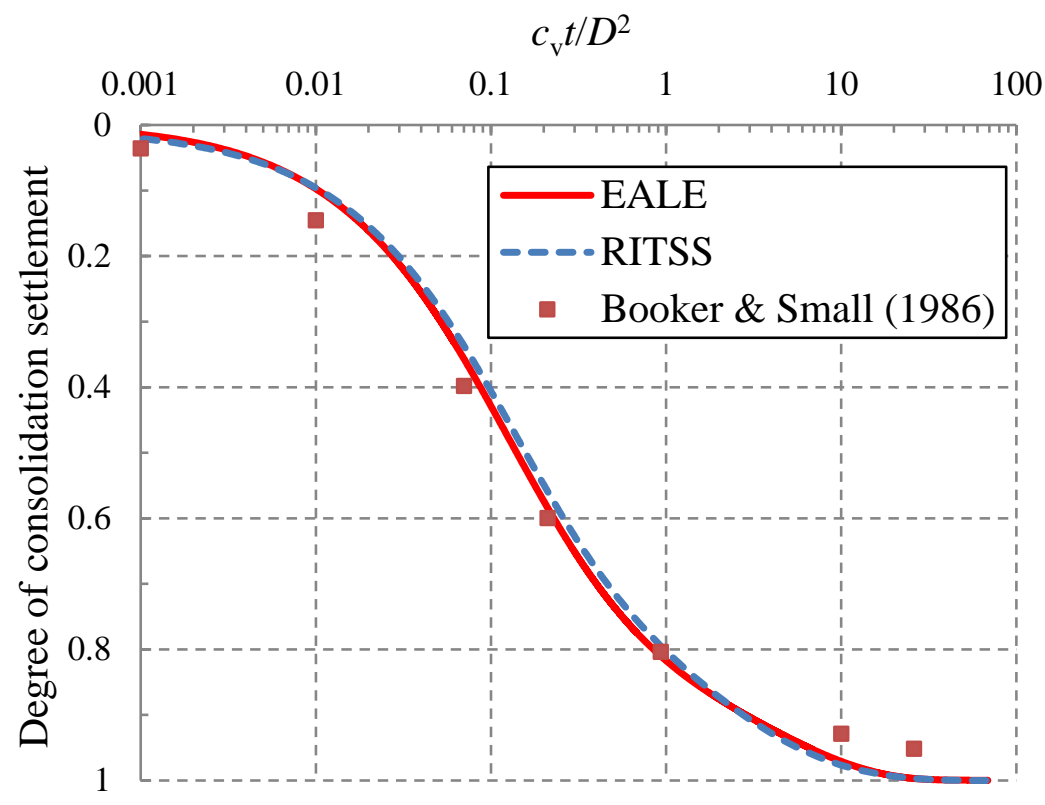

(b) Normalised results

Figure 7 Settlement underneath circular footing

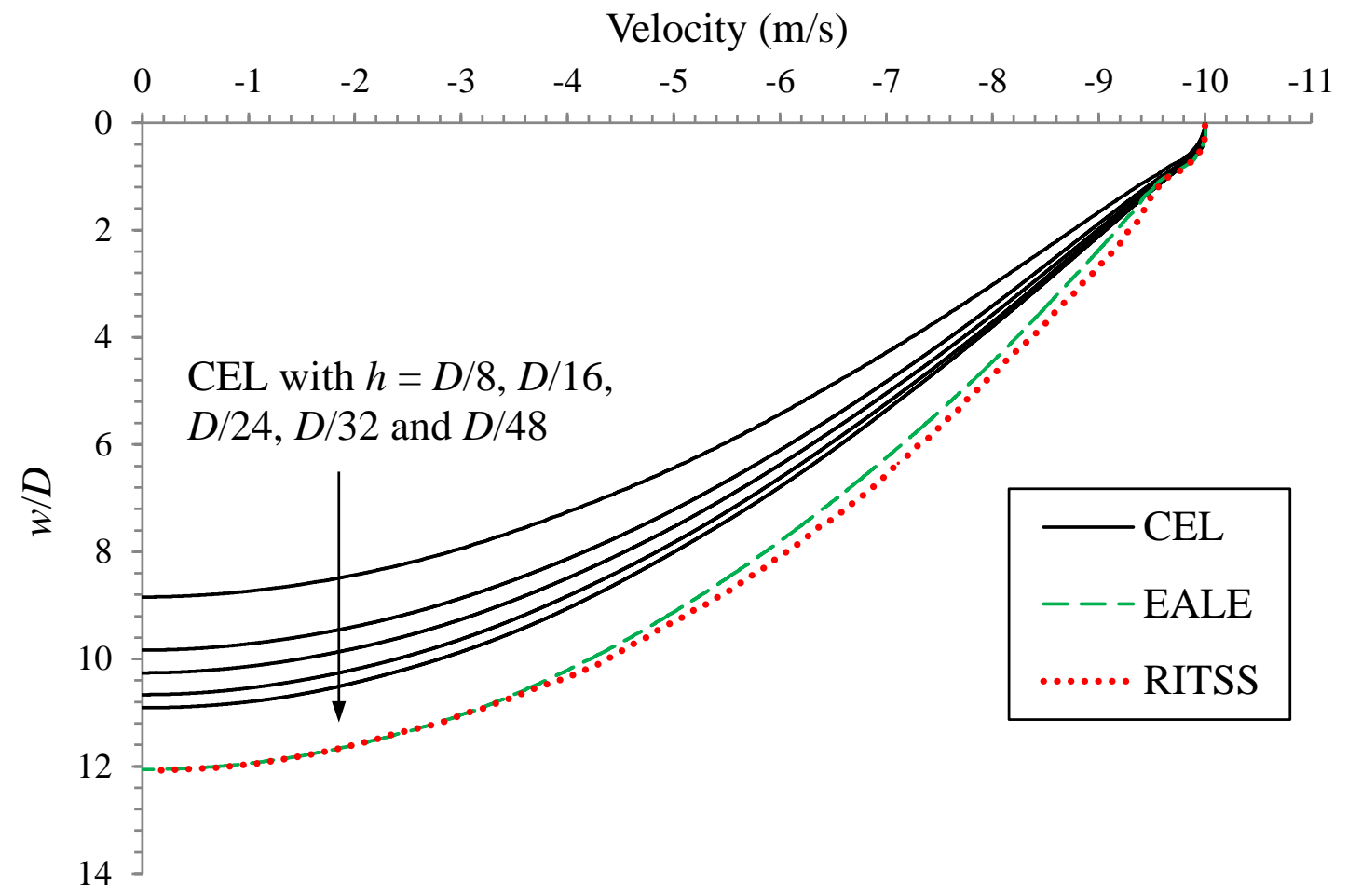

Figure 8 Dynamic penetration of free falling cone 